\title{
Transforming growth factor-beta and Forkhead box $O$ transcription factors as cardiac fibroblast regulators
}

\author{
Ignacio Norambuena-Soto ${ }^{1}$, Constanza Núñez-Soto ${ }^{1}$, Fernanda Sanhueza-Olivares ${ }^{1}$, Nicole \\ Cancino-Arenas ${ }^{1}$, David Mondaca-Ruff ${ }^{1}$, Raul Vivar ${ }^{2}$, Guillermo Díaz-Araya ${ }^{1}$, Rosemarie \\ Mellado $^{3}$, Mario Chiong ${ }^{1,4, *}$ \\ ${ }^{1}$ Facultad de Ciencias Quimicas y Farmacéuticas, Universidad de Chile, Santiago, Chile; \\ ${ }^{2}$ Facultad de Medicina; Universidad de Chile, Santiago, Chile; \\ ${ }^{3}$ Facultad de Química, Pontificia Universidad Católica de Chile, Santiago, Chile; \\ ${ }^{4}$ Centro de Estudios Moleculares de la Célula, Universidad de Chile, Santiago, Chile.
}

\begin{abstract}
Summary Fibroblasts play several homeostatic roles, including electrical coupling, paracrine signaling and tissue repair after injury. Fibroblasts have low secretory activity. However, in response to injury, they differentiate to myofibroblasts. These cells have an increased extracellular matrix synthesis and secretion, including collagen fibers, providing stiffness to the tissue. In pathological conditions myofibroblasts became resistant to apoptosis, remaining in the tissue, causing excessive extracellular matrix secretion and deposition, which contributes to the progressive tissue remodeling. Therefore, increased myofibroblast content within damaged tissue is a characteristic hallmark of heart, lung, kidney and liver fibrosis. Recently, it was described that cardiac fibroblast to myofibroblast differentiation is triggered by the transforming growth factor $\beta 1$ (TGF- $\beta 1$ ) through a Smad-independent activation of Forkhead box $O$ (FoxO). FoxO proteins are a transcription factor family that includes FoxO1, FoxO3, FoxO4 and FoxO6. In several cells types, they play an important role in cell cycle arrest, oxidative stress resistance, cell survival, energy metabolism, and cell death. Here, we review the role of FoxO family members on the regulation of cardiac fibroblast proliferation and differentiation.
\end{abstract}

Keywords: TGF- $\beta$, FoxO, transcription factor, fibroblast, myofibroblast, fibrosis

\section{Introduction}

In cardiac tissue there are three main cell types: cardiomyocytes, vascular cells, and fibroblasts. Fibroblasts represent around $30 \%$ of the total heart cell population (1). Fibroblasts are flat spindle-shaped cells of mesenchymal origin responsible for extracellular matrix homeostasis $(2,3)$. Fibroblasts do not possess a definitive cell marker, so their characterization relies on morphological, proliferative, and phenotypical

Released online in J-STAGE as advance publication February 24, 2017.

*Address correspondence to

Dr. Mario Chiong, Facultad de Ciencias Químicas y Farmacéuticas, Universidad de Chile, Sergio Livingstone 1007, Santiago 8380492, Chile.

E-mail: mchiong@ciq.uchile.cl characteristics (2). Although, a protein that is expressed exclusively in fibroblasts is not described, in human and mouse cardiac tissue, fibroblasts can be identified by the expression of collagen-activated receptor tyrosine kinase discoidin domain receptor 2 (DDR2) and intermediatefilament associated calcium-binding protein S100A4 (or fibroblast-specific protein 1 [FSP-1]) $(1,4)$. Cardiac fibroblasts play various roles among which electrical coupling, paracrine signaling and tissue repair after injury are the most described (5).

In a normal situation, cardiac fibroblasts have low secretory activity and produce extracellular matrix proteins, such as collagen types I and III, laminin and fibronectin. They also synthesize and secrete various metalloproteinases that are responsible for extracellular matrix degradation, and several growth factors and cytokines (6). However, upon tissue injury, cardiac fibroblasts differentiate to cardiac myofibroblasts. 


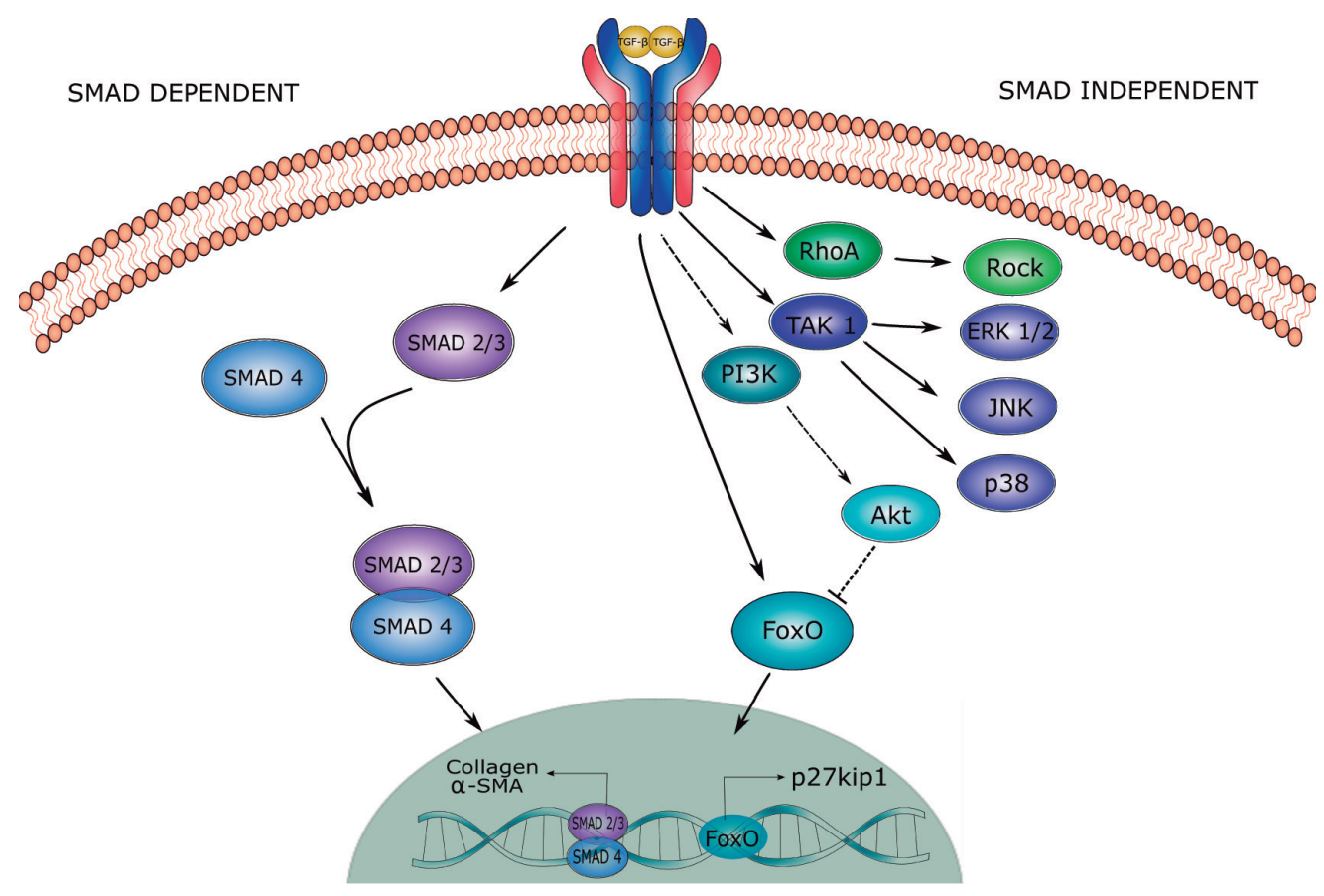

Figure 1. Smad-dependent and Smad independent signaling pathways triggered by TGF- $\beta$. The canonical transductional pathway for TGF- $\beta$ involves the Smad-dependent signaling pathway. Once activated, T $\beta$ RI phosphorylates Smad $2 / 3$ which dissociates from the receptor and binds to Smad 4. Later, Smad 2/3-Smad 4 complex translocates to the nucleus and regulates the expression of several genes, e.g. collagen, fibronectin, $\alpha$-SMA. On the other hand, in the Smad-independent pathway, TGF- $\beta$ activates TAK1, which phosphorylates and activates ERKs, p38, and JNK. Also, TGF- $\beta$ activates ROCK by RhoA. New evidence has shown that in T cells, TGF- $\beta 1$ activates the PI3K/Akt pathway, which phosphorylates and inhibits FoxO transcription factors. But in cardiac fibroblast, TGF- $\beta 1$ activates FoxO promoting gene expression, e.g. p27kip1.

Myofibroblasts are characterized by an augmented capacity to synthesize and secrete collagen and other extracellular matrix proteins important for scar formation and wound healing (5). They have lower migratory and proliferative capacity than cardiac fibroblasts (7) but with an increased resistance to apoptosis (8). Furthermore, from a structural point of view, myofibroblasts have a specialized contractile protein, $\alpha$-smooth muscle actin $(\alpha$-SMA), commonly used as a marker for differentiation $(9,10)$. Due to the reduced susceptibility to apoptosis, myofibroblasts remain in the myocardial tissue, causing excessive secretion and deposition of extracellular matrix components, increasing myocardial tissue stiffness $(4,11)$, which can contribute to the progressive cardiac pathological remodeling $(12,13)$. Furthermore, the fibrotic scar can cause disruption of electrical signaling and muscle contraction which eventually result in heart failure (5). Participation of myofibroblasts in pathological fibrosis is not limited to the heart (14), but is a common hallmark of all fibrotic processes, including lung (15) and liver (16) among others. Therefore, the control of fibroblast to myofibroblast differentiation is an interesting target in order to prevent adverse consequences of tissue fibrosis and remodeling.

\section{TGF-B}

Transforming growth factor- $\beta$ (TGF- $\beta$ ) are cytokines belonging to a peptide family with multiple physiological and pleiotropic functions, including inflammatory and immune responses, cell proliferation, growth, differentiation and collagen production (17-20). In mammals, three isoform (TGF- $\beta 1, T G F-\beta 2, T G F-\beta 3)$ have been described, each isoform encoded by different genes (21). TGF- $\beta 1$ is expressed in a broad range of cells including fibroblasts, T-cells, B-cells, macrophages, and epithelial and endothelial cells and almost all of them have specific receptors for this peptide (22-24). TGF- $\beta 1$, TGF- $\beta 2$ and TGF- $\beta 3$ are released in a nonactive latent form (L-TGF- $\beta$ ) that binds to the L-TGF- $\beta$ binding protein 1 (LTBP1) in the extracellular matrix. In order to be activated L-TGF- $\beta$ is proteolyzed by thrombospondin- 1 or plasmin (25). TGF- $\beta 1$, TGF- $\beta 2$, and TGF- $\beta 3$ all function through the same receptor signaling system (22). TGF- $\beta 1$ receptors (T $\beta R$ ) are single transmembrane serine/threonine kinase receptors (17). TGF- $\beta 1$ binding to type II receptor (TRRII) homodimer induces the recruitment of a receptor type I (TRRI) homodimer resulting in a heterotetramer complex. The T $\beta$ RII serine/threonine kinase catalyzes unidirectional phosphorylation of TRRI, which activates the receptor $(26,27)$.

Subsequently, Smad-dependent and Smad independent signaling pathways are activated (Figure $1)$. The Smad-dependent signaling pathway is the canonical transductional pathway for TGF- $\beta$. Activated T $\beta R I$ phosphorylates Smad $2 / 3$ at the SSXS C-terminal motif. Later, Smad2/3 dissociates from the receptor 
and binds to a coSmad, e.g. Smad 4. This complex translocates to the nucleus and acts as a transcription factor controlling the expression of several genes (28). In the Smad-independent pathway many signaling cascades are described. TGF- $\beta$ rapidly activates Rho family guanosine triphophatases (GTPases) (29). TGF- $\beta$ dependent activation of RhoA pathway induces the translocation of myocardin related transcription factor A (MRTF-A) to the nucleus to regulate a profibrotic response (30,31). TGF- $\beta$ activates mitogen-activated protein kinases, including (extracellular signal-regulated kinases) ERKs, p38, and c-Jun N-terminal kinases (JNKs) through their upstream kinase activators such as transforming growth factor- $\beta$ activated kinase- 1 (TAK1) (29). In human lung fibroblasts, TGF- $\beta$ induction of endothelin-1 occurs via activation of JNK, and endothelin-1 acts via the endothelin-A/B receptors to initiate Rac/Akt/Phosphatidylinositol-4,5-bisphosphate 3-kinase (PI3K) signaling, resulting in expression of $\alpha$-SMA. TGF- $\beta 1$ can also activate the PI3K pathway which in turn induces Akt by selective phosphorylation at S473, but not at T308. Akt, in turn, phosphorylates and inhibits FoxO transcription factors, associated with the prevention of regulatory $\mathrm{T}$ cell differentiation (32).

\section{TGF- $\beta$ and fibroblasts}

TGF- $\beta 1$ plays an important role in fibrosis, because it mediates the differentiation of fibroblast into myofibroblast $(7,33)$. Several line of evidences support the importance of TGF- $\beta$ in the induction and maintenance of the fibrotic response. In cultured fibroblasts, TGF- $\beta$ directly induces collagen production and contraction by fibroblasts, including those isolated from heart tissue (34). Subcutaneous injection of TGF- $\beta$ results in enhanced deposition of extracellular matrix (35). Treatment of wounds with TGF- $\beta$ promotes wound closure and scarring (36). Moreover, blocking TGF- $\beta$ with antibodies (37) or anti-sense oligonucleotides (38) reduces collagen deposition and scarring. Overexpression of TGF- $\beta$ in heart induces myocardial fibrosis (39), while blunting TGF- $\beta 1$ expression, using TGF- $\beta$ knock out (KO) mice or dominant negative TGF $-\beta$ receptor mice, markedly reduced collagen deposition (40).

Besides TGF- $\beta 1$, fibroblast to myofibroblast differentiation also requires mechanical tension, which is regulated by the interaction between the contractile activity of myofibroblasts and the stiffness of the extracellular matrix $(41,42)$. Inhibition of mechanical stress triggers $\alpha$-SMA protein level decrease (42), a widely used marker of myofibroblast differentiation. Also, during wound healing, fibroblasts express the ED-A fibronectin, which is crucial for fibroblast to myofibroblast differentiation and for a normal scar formation $(43,44)$. Furthermore, it is demonstrated that ED-A fibronectin is necessary, but not sufficient, to induce the myofibroblast phenotype, but it exerts a permissive effect on TGF- $\beta$ activity (43).

\section{FoxO transcription factors}

A recent study in cardiac fibroblasts, Vivar et al. demonstrated that TGF- $\beta 1$ induces differentiation of fibroblast into myofibroblast in a FoxO1 dependent manner (34). The forkhead transcription factor superfamily is characterized by a winged-helix DNA binding motif and the forkhead domain (45). The mammalian forkhead transcription factors of the $\mathrm{O}$ class (FoxO) have four members: FoxO1, FoxO3, FoxO4, and FoxO6. FoxO1 and FoxO3 are expressed in most tissues and cells, including fibroblasts (46). FoxO4 is highly expressed in muscle, kidney, and colorectal tissue while FoxO6 has been seen only in the central nervous system (47). FoxOs recognize two response elements and binds to the insulin-responsive element (5'-(C/A)(A/C)AAA(C/T)AA-3') with higher affinity than to the Daf-16 family member binding element (5'-GTAAA(T/C)AA-3') (48).

Hosaka et al. developed $\mathrm{KO}$ mice for FoxO1, FoxO3 and FoxO4 (49). FoxO1 KO is lethal in embryonic stages due to lack of vascular development. FoxO3 and FoxO4 KO mice are viable and show normal growth in appearance, but have altered lymph proliferation, widespread organ inflammation (50) and decline in the neural stem cell pool (51), as compared to wild type mice. FoxO3 KO female mice showed irregular ovarian follicle growth causing infertility (49). FoxO4 KO exacerbates colitis in response to inflammatory stimuli (52). FoxO6 KO mice display normal learning but impaired memory consolidation (53).

FoxO transcriptional activity is regulated by different post-translational modifications, mainly through phosphorylation, acetylation and ubiquitination $(54,55)$. These modifications can activate or inactivate the function as a transcription factor. They alter its subcellular localization, modify the DNA binding affinity, and change the pattern of transcriptional activity for specific target. The main pathway regulating FoxO activity is the phosphorylation by Akt in three different sites (T24, S256 and S319), which favors their interaction with 14-3-3 adapter protein inhibiting its interaction with DNA and promoting their nuclear export and subsequent degradation by proteasome $(55,56)$. Also, deacetylase protein sirtuin, such as SIRT1, can deacetylate FoxO, preventing its phosphorylation by Akt, leading to its activation (57).

Additionally to Akt, there are other kinases that can phosphorylate FoxO. ERK (58), IkB kinase (IKK) (59) and casein kinase 1 (CK1) (60) negatively regulate FoxO activity by inducing active exportation of the nucleus to the cytosol. On the other hand, under general stress conditions, other kinases can promote FoxO nuclear import. Oxidative stress induces FoxO 
phosphorylation by JNK and Mammalian Ste20like kinase (MST1), and activates the expression of antioxidant genes such as superoxide dismutase. Also, by nutrient stress, AMP-activated protein kinase (AMPK) phosphorylates FoxO, and induce energy metabolism related gene expression (45).

\section{FoxO and fibroblasts}

Several articles have described the role of FoxO in fibroblast physiology. There are only few articles describing role of FoxO in cardiac fibroblast. In order to obtain a more wide perspective of FoxO actions, fibroblast from other sources were included in this review. Therefore, here we summarize the available information and highlight its relevance for fibroblast to myofibroblast differentiation.

\subsection{FoxO1}

In a model of iron-overload cardiomyopathy, cardiac fibrosis was observed associated with an increase of $\alpha$-SMA levels. These data suggest that iron overload induces cardiac fibroblast to myofibroblast differentiation. Interestingly, in these cells an increase in FoxO1 nuclear localization was observed (61). In neonatal cardiac fibroblast TGF- $\beta 1$ induces fibroblast to myofibroblast differentiation, which is completely prevented by FoxO1 inhibition (34). In this cell model, TGF- $\beta 1$ increases in a time and dose dependent manner FoxO1 mRNA and protein levels, induces FoxO1 dephosphorylation, increases FoxO1 nuclear translocation and increases FoxO1 target gene transcription (34). Moreover, FoxO1 overexpression enhances TGF- $\beta 1$ effects on cardiac fibroblasts (34). Taken together, these data suggest that FoxO1 is required for TGF- $\beta 1$ dependent fibroblast to myofibroblast differentiation. Remains to be elucidated whether the participation of FoxO1 is exclusively associated to TGF- $\beta 1$ or is a general mediator of fibroblast to myofibroblast differentiation.

One of the main skin alteration that take place during wound healing remodeling is the elimination of fibroblasts by apoptosis $(62,63)$. FoxO transcription factors play a key role in the regulation of this process (64). In primary human dermal fibroblasts, TNF $\alpha$ activates FoxO1 expression, decreasing fibroblast proliferation $(64,65)$. Silencing of FoxO1 using a siRNA, reduced TNF $\alpha$ induced fibroblast apoptosis as well as a wide range of $\mathrm{TNF} \alpha$-induced pro-apoptotic genes (64). Both results suggest that the ability of TNF $\alpha$ to induce dermal fibroblast apoptosis and to inhibit their proliferation requires FoxO1 activation. Skin damage by arsenic acid activates FoxO1 through a mechanism involving MST1 activation by a reactive oxygen species (ROS) dependent mechanism. Consequently, FoxOs translocate to nucleus and inhibit cell proliferation of mouse skin fibroblasts (66). In human foreskin fibroblasts, growth factors such as PDGF, FGF and IGF-I can inhibit the expression of FoxO genes, promoting their proliferation (67). PDGF promoted FoxO1 phosphorylation and translocation from the nucleus to the cytosol, and FoxO1 inhibition using a shRNA, led to fibroblast proliferation (67). FoxO1 inhibition of human foreskin fibroblast proliferation is partially due to an increase in high-mobility group-box protein 1 expression (68). Additionally, in primary human adult dermal fibroblasts, dehydroabietic acid can reverse TNF $\alpha$ stimulated cell responses, including FoxO1 activation, and increase fibroblast proliferation (65). Interestingly, in excisional wounds from mice with type 1 or type 2 diabetes, increased levels of apoptosis, TNF $\alpha$ and FoxO1 activation was observed in fibroblasts $(69,70)$. In diabetic $d b / d b$ mice, FoxO1 regulates cell cycle genes in a TNF $\alpha-$ independent manner, and FoxO1 inhibition using a siRNA, blocked the TNF $\alpha$-induced pro-inflammatory genes (70). Therefore, in patients with diabetes, FoxO1 could be an important target for the treatment of diabetic foot and other skin complications. Taken together, these results suggest that FoxO1 is an important regulator of wound healing, through the control of fibroblast apoptosis and proliferation. However, in none of these works a relationship between proliferation and apoptosis with fibroblast to myofibroblast differentiation was studied.

Prostaglandin E2 (PGE2) signaling is an important inhibitor of primary fetal and adult lung fibroblast to myofibroblast differentiation, by counteracting the effects of TGF $\beta 1$ (71). Additionally, PGE2 can also reverse the established myofibroblast differentiation (72). On the other hand, PGE2 promotes FoxO1 phosphorylation and nuclear export by PI3K/Akt activation (73). However, whether FoxO1 is involved in the PGE2-induced reversion of myofibroblast differentiation remains unexplored.

In the liver, a relationship between FoxO1 and the differentiation of hepatic stellate cells to myofibroblasts has also been found. In a model of mice hepatic fibrosis, FoxO1 inhibition in hepatic stellate cells, assessed by an increase in FoxO1 phosphorylation and its subsequent exclusion of the nucleus, induces an increase in $\alpha-S M A$ levels (74). This data suggest that in this mice model, FoxO1 inhibits the hepatic stellate cells to myofibroblast differentiation. However, an inversed relationship was observed in humans. Patients with nonalcoholic steatohepatitis had low levels of phosphorylated FoxO1 associated with an increased type 1 collagen levels (75). These contradictory evidences point out that the role of FoxO1 in the hepatic stellate cells to myofibroblasts differentiation needs to be further analyzed.

\section{2. $\mathrm{FoxO}_{3}$}

In adult rat cardiac fibroblasts, FoxO3a regulates cell 
cycle progression by increasing p27kip1 expression, an inhibitor of cyclin dependent kinase, through an ERK1/2 dependent signaling pathway (76). In the heart of diabetic mice elevated collagen levels is associated with low levels of $\mathrm{FoxO} 3$ (77). Additionally, FoxO3 inactivation by resveratrol decreases cardiac fibrosis produced by exercise (78). However, in this model, exercise-induced fibrosis is not related with $\mathrm{FoxO} 3$ phosphorylation (78). All these data suggest that FoxO3 inactivation is associated with a decreased fibrosis, probably by regulating proliferation and apoptosis sensitivity.

In a model of renal fibrosis induced by unilateral ureteral obstruction, accumulation of collagen and increased expression of $\alpha$-SMA is associated with FoxO3 inactivation (79). Moreover, increased $\mathrm{FoxO} 3$ expression by silencing microRNA-132, a microRNA that downregulates FoxO3 mRNA, selectively inhibits fibroblast proliferation and decrease renal fibrosis (80). Primary fibroblast cultures obtained from idiopathic pulmonary fibrosis (IPF) are characterized by their ability to elude the proliferation-suppressive properties of polymerized type I collagen. This ability involves the aberrant activation of the PI3K/Akt signaling pathway that inactivates FoxO3a, resulting in p27kip1 down regulation and a decreased sensitivity to apoptosis $(81,82)$. Moreover, in IPF fibroblasts FoxO3a is further inhibited by microRNA-96 (83). Decreased sensitivity to apoptosis is due to caveolin 1 downregulation which decrease Fas levels (81). On the other hand, reduced $\mathrm{FoxO} 3$ expression is sufficient to generate a hyperproliferative state in IPF fibroblasts (84). All these findings show that inhibition of $\mathrm{FoxO} 3$ is responsible for the maintenance of the proliferative pathological fibroblast phenotype, which contributes to the development of renal or pulmonary fibrosis.

In the liver, $\mathrm{FoxO} 3$ also regulates the proliferation and apoptosis of hepatic stellate cells $(85,86)$. TRAIL, a member of the TNF $\alpha$ family, induces FoxO3 activation by promoting its nuclear translocation and thereby increasing apoptosis in the LX-2 cell line, an immortalized human hepatic stellate cells (86). Moreover, FoxO3 activation also promotes an increase in p27kip1 expression, causing a decrease in LX-2 proliferation (85). Therefore, data support the notion that $\mathrm{FoxO} 3$ regulates proliferation and apoptosis sensitivity rather than hepatic stellate cell to myofibroblast differentiation.

In primary culture of human dermal fibroblasts, FoxO3a down regulation by siRNA induces a senescent phenotype (87). In the same way, UV treatment of human dermal fibroblasts also induce the senescent phenotype associated with FoxO3 phosphorylation. Prevention of FoxO3 phosphorylation impedes block senescent phenotype induced by UV treatment (88). In a model of aging induced by DNA damage in mice embryonic fibroblast (MEF) cells, activation of p53 inhibits FoxO3a transcriptional activity by phosphorylation and subcellular localization change

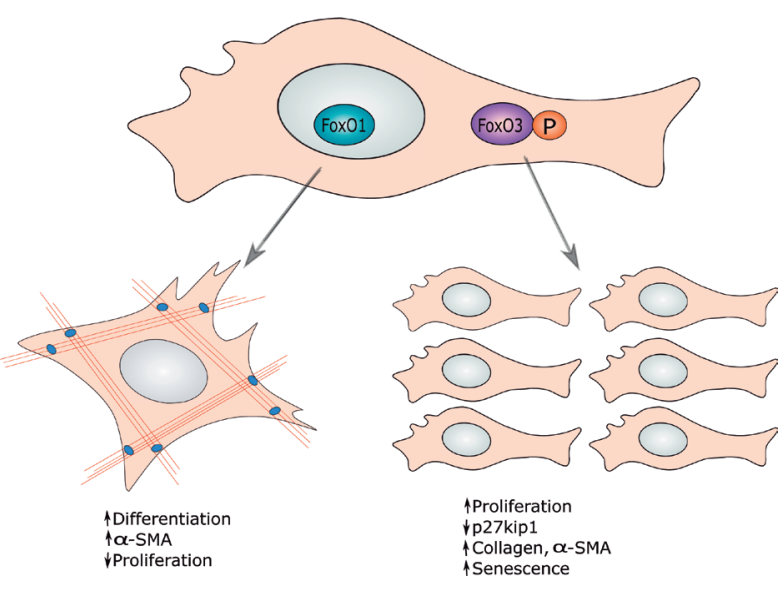

Figure 2. Proposed actions of FoxO transcription factors in fibroblasts. FoxO1 regulates fibroblast to myofibroblast differentiation, and increases both $\alpha$-SMA protein levels and cell proliferation. On the other hand, phospho-FoxO3 ( $\mathrm{p}$ FoxO3) translocates to the cytosol and promotes cell proliferation by decreasing p27kipl gene expression. Decrease of FoxO3 activity also increases collagen and $\alpha$-SMA protein levels and triggers fibroblast senescence.

(89). This phosphorylation could be mediated by serumand glucocorticoid-inducible kinase 1 (SGK1) due to p53-dependent activation of ERK1/2 (89). These data indicate that FoxO3a regulates senescence and cell cycle progression in fibroblast.

\subsection{FoxO4}

There are only few studies with FoxO4 and fibroblasts. In 3T3L1 fibroblasts, FoxO4 regulates the late steps of cholesterol biosynthesis due to repression of cytochrome P450 sterol 14 $\alpha$-demethylase (CYP51) (90). The mechanism involves FoxO4 binding to sterol regulatory element-binding protein 2 to upregulate CYP51 and FoxO4 binding to hypoxia-inducible factor-2 to regulate CYP51 repression (91). Therefore, until now, FoxO4 has only been associated to the regulation of cholesterol metabolism in fibroblast.

\section{Conclusions}

Figure 2 shows the general actions that are regulated by FoxO transcription factors in fibroblasts. The main action of FoxO1 seems to be the regulation of the fibroblast to myofibroblast differentiation process, especially in cardiac fibroblasts. FoxO1 is regulated by a SMAD independent pathway downstream TGF- $\beta 1$ receptor. Moreover, FoxO1 has also been involved in the hepatic stellar cell to myofibroblast differentiation in the liver, and possibly in the PGE2-induced reversion of myofibroblast differentiation. In the other hand, FoxO3 shows a close relationship with proliferation, senescence, and apoptosis sensitization in fibroblasts. FoxO3 deregulation is associated with an exacerbated proliferation of fibroblasts leading to renal, pulmonary, skin and cardiac fibrosis. In liver, $\mathrm{FoxO} 3$ has also 
been linked to fibrosis by regulating hepatic stellar cell proliferation. Finally, FoxO4 has only been described as a regulator of cholesterol metabolism. Deciphering the role of FoxO transcription factors could be useful to design effective therapeutic approaches for the treatment of different types of fibrosis.

\section{Acknowledgements}

This research was funded in part by Comision Nacional de Ciencia y Tecnologia (CONICYT), Chile (FONDECYT 1140329 to M.C.; FONDECYT 11160531 to R.V., FONDECYT 1130300 to G.D.A.). IN-S and DM-R hold CONICYT PhD fellowships.

\section{References}

1. Banerjee I, Fuseler JW, Price RL, Borg TK, Baudino TA. Determination of cell types and numbers during cardiac development in the neonatal and adult rat and mouse. Am J Physiol Heart Circ Physiol. 2007; 293:H18831891.

2. Krenning G, Zeisberg EM, Kalluri R. The origin of fibroblasts and mechanism of cardiac fibrosis. J Cell Physiol. 2010; 225:631-637.

3. Souders CA, Bowers SL, Baudino TA. Cardiac fibroblast: The renaissance cell. Circ Res. 2009; 105:1164-1176.

4. Camelliti P, Borg TK, Kohl P. Structural and functional characterisation of cardiac fibroblasts. Cardiovasc Res. 2005; 65:40-51.

5. Lighthouse JK, Small EM. Transcriptional control of cardiac fibroblast plasticity. J Mol Cell Cardiol. 2016; 91:52-60.

6. Chistiakov DA, Orekhov AN, Bobryshev YV. The role of cardiac fibroblasts in post-myocardial heart tissue repair. Exp Mol Pathol. 2016; 101:231-240.

7. Petrov VV, van Pelt JF, Vermeesch JR, Van Duppen VJ, Vekemans K, Fagard RH, Lijnen PJ. TGF-beta1-induced cardiac myofibroblasts are nonproliferating functional cells carrying DNA damages. Exp Cell Res. 2008; 314:1480-1494.

8. Copaja M, Venegas D, Aranguiz P, Canales J, Vivar R, Catalan M, Olmedo I, Rodriguez AE, Chiong M, Leyton L, Lavandero S, Diaz-Araya G. Simvastatin induces apoptosis by a Rho-dependent mechanism in cultured cardiac fibroblasts and myofibroblasts. Toxicol Appl Pharmacol. 2011; 255:57-64.

9. Hinz B, Gabbiani G. Mechanisms of force generation and transmission by myofibroblasts. Curr Opin Biotechnol. 2003; 14:538-546.

10. Hinz B. Masters and servants of the force: The role of matrix adhesions in myofibroblast force perception and transmission. Eur J Cell Biol. 2006; 85:175-181.

11. Turner NA, Porter KE, Smith WH, White HL, Ball SG, Balmforth AJ. Chronic beta2-adrenergic receptor stimulation increases proliferation of human cardiac fibroblasts via an autocrine mechanism. Cardiovasc Res. 2003; 57:784-792.

12. Gabbiani G. The myofibroblast in wound healing and fibrocontractive diseases. J Pathol. 2003; 200:500-503.

13. Ikeuchi M, Tsutsui H, Shiomi T, Matsusaka H,
Matsushima S, Wen J, Kubota T, Takeshita A. Inhibition of TGF-beta signaling exacerbates early cardiac dysfunction but prevents late remodeling after infarction. Cardiovasc Res. 2004; 64:526-535.

14. Swaney JS, Roth DM, Olson ER, Naugle JE, Meszaros JG, Insel PA. Inhibition of cardiac myofibroblast formation and collagen synthesis by activation and overexpression of adenylyl cyclase. Proc Natl Acad Sci U S A. 2005; 102:437-442.

15. Usuki J, Matsuda K, Azuma A, Kudoh S, Gemma A. Sequential analysis of myofibroblast differentiation and transforming growth factor-beta1/Smad pathway activation in murine pulmonary fibrosis. J Nippon Med Sch. 2012; 79:46-59.

16. Kisseleva T, Cong M, Paik Y, Scholten D, Jiang C, Benner C, Iwaisako K, Moore-Morris T, Scott B, Tsukamoto H, Evans SM, Dillmann W, Glass CK, Brenner DA. Myofibroblasts revert to an inactive phenotype during regression of liver fibrosis. Proc Natl Acad Sci U S A. 2012; 109:9448-9453.

17. Biernacka A, Dobaczewski M, Frangogiannis NG. TGFbeta signaling in fibrosis. Growth Factors. 2011; 29:196202.

18. Salazar KD, Lankford SM, Brody AR. Mesenchymal stem cells produce Wnt isoforms and TGF-betal that mediate proliferation and procollagen expression by lung fibroblasts. Am J Physiol Lung Cell Mol Physiol. 2009; 297:L1002-1011.

19. Ma HL, Zhao XF, Chen GZ, Fang RH, Zhang FR. Silencing NLRC5 inhibits extracellular matrix expression in keloid fibroblasts via inhibition of transforming growth factor-beta1/Smad signaling pathway. Biomed Pharmacother. 2016; 83:1016-1021.

20. Zhang M, Liao Y, Lonnerdal B. EGR-1 is an active transcription factor in TGF-beta2-mediated small intestinal cell differentiation. J Nutr Biochem. 2016; 37:101-108.

21. Schiller M, Javelaud D, Mauviel A. TGF-beta-induced SMAD signaling and gene regulation: Consequences for extracellular matrix remodeling and wound healing. J Dermatol Sci. 2004; 35:83-92.

22. Letterio JJ, Roberts AB. Regulation of immune responses by TGF-beta. Annu Rev Immunol. 1998; 16:137-161.

23. Westergren-Thorsson G, Hernnas J, Sarnstrand B, Oldberg A, Heinegard D, Malmstrom A. Altered expression of small proteoglycans, collagen, and transforming growth factor-beta 1 in developing bleomycin-induced pulmonary fibrosis in rats. J Clin Invest. 1993; 92:632-637.

24. Huang M, Sharma S, Zhu LX, Keane MP, Luo J, Zhang L, Burdick MD, Lin YQ, Dohadwala M, Gardner B, Batra RK, Strieter RM, Dubinett SM. IL-7 inhibits fibroblast TGF-beta production and signaling in pulmonary fibrosis. J Clin Invest. 2002; 109:931-937.

25. Leask A. TGFbeta, cardiac fibroblasts, and the fibrotic response. Cardiovasc Res. 2007; 74:207-212.

26. Goumans MJ, Valdimarsdottir G, Itoh S, Rosendahl A, Sideras P, ten Dijke P. Balancing the activation state of the endothelium via two distinct TGF-beta type I receptors. EMBO J. 2002; 21:1743-1753.

27. Van Geest RJ, Klaassen I, Vogels IM, Van Noorden CJ, Schlingemann RO. Differential TGF-\{beta $\}$ signaling in retinal vascular cells: A role in diabetic retinopathy? Invest Ophthalmol Vis Sci. 2010; 51:1857-1865.

28. Chen G, Wang T, Uttarwar L, vanKrieken R, Li R, 
Chen X, Gao B, Ghayur A, Margetts P, Krepinsky JC. SREBP-1 is a novel mediator of TGFbetal signaling in mesangial cells. J Mol Cell Biol. 2014; 6:516-530.

29. Attisano L, Wrana JL. Signal transduction by the TGFbeta superfamily. Science. 2002; 296:1646-1647.

30. Korol A, Taiyab A, West-Mays JA. RhoA/ROCK signaling regulates TGFbeta-induced epithelialmesenchymal transition of lens epithelial cells through MRTF-A. Mol Med. 2016; 22.

31. Lei H, Wu D, Wang JY, Li L, Zhang CL, Feng H, Fu FY, Wu LL. C1q/tumor necrosis factor-related protein-6 attenuates post-infarct cardiac fibrosis by targeting RhoA/MRTF-A pathway and inhibiting myofibroblast differentiation. Basic Res Cardiol. 2015; 110:35.

32. Kurebayashi Y, Baba Y, Minowa A, Nadya NA, Azuma M, Yoshimura A, Koyasu S, Nagai S. TGF-betainduced phosphorylation of Akt and Foxo transcription factors negatively regulates induced regulatory $\mathrm{T}$ cell differentiation. Biochem Biophys Res Commun. 2016; 480:114-119.

33. Zhou JP, Tang W, Feng Y, Li N, Gu CJ, Li QY, Wan HY. Angiotensin-(1-7) decreases the expression of collagen I via $\mathrm{TGF}-$ beta $1 / \mathrm{Smad} 2 / 3$ and subsequently inhibits fibroblast-myofibroblast transition. Clin Sci (Lond). 2016; 130:1983-1991.

34. Vivar R, Humeres C, Munoz C, Boza P, Bolivar S, Tapia F, Lavandero S, Chiong M, Diaz-Araya G. FoxO1 mediates TGF-beta1-dependent cardiac myofibroblast differentiation. Biochim Biophys Acta. 2016; 1863:128138.

35. Mori T, Kawara S, Shinozaki M, Hayashi N, Kakinuma T, Igarashi A, Takigawa M, Nakanishi T, Takehara K. Role and interaction of connective tissue growth factor with transforming growth factor-beta in persistent fibrosis: A mouse fibrosis model. J Cell Physiol. 1999; 181:153159.

36. Duncan MR, Frazier KS, Abramson S, Williams S, Klapper H, Huang X, Grotendorst GR. Connective tissue growth factor mediates transforming growth factor betainduced collagen synthesis: Down-regulation by cAMP. FASEB J. 1999; 13:1774-1786.

37. Shah M, Foreman DM, Ferguson MW. Neutralising antibody to TGF-beta 1,2 reduces cutaneous scarring in adult rodents. J Cell Sci. 1994; 107 ( Pt 5):1137-1157.

38. Cordeiro MF, Mead A, Ali RR, Alexander RA, Murray S, Chen C, York-Defalco C, Dean NM, Schultz GS, Khaw PT. Novel antisense oligonucleotides targeting TGF-beta inhibit in vivo scarring and improve surgical outcome. Gene Ther. 2003; 10:59-71.

39. Seeland U, Haeuseler C, Hinrichs R, Rosenkranz S, Pfitzner T, Scharffetter-Kochanek K, Bohm M. Myocardial fibrosis in transforming growth factorbeta(1) (TGF-beta(1)) transgenic mice is associated with inhibition of interstitial collagenase. Eur J Clin Invest. 2002; 32:295-303.

40. Letterio JJ, Bottinger EP. TGF-beta knockout and dominant-negative receptor transgenic mice. Miner Electrolyte Metab. 1998; 24:161-167.

41. Arora PD, Narani N, McCulloch CA. The compliance of collagen gels regulates transforming growth factor-beta induction of alpha-smooth muscle actin in fibroblasts. Am J Pathol. 1999; 154:871-882.

42. Hinz B, Mastrangelo D, Iselin CE, Chaponnier C, Gabbiani G. Mechanical tension controls granulation tissue contractile activity and myofibroblast differentiation. Am J Pathol. 2001; 159:1009-1020.

43. Serini G, Bochaton-Piallat ML, Ropraz P, Geinoz A, Borsi L, Zardi L, Gabbiani G. The fibronectin domain ED-A is crucial for myofibroblastic phenotype induction by transforming growth factor-beta1. J Cell Biol. 1998; 142:873-881.

44. Muro AF, Chauhan AK, Gajovic S, Iaconcig A, Porro F, Stanta G, Baralle FE. Regulated splicing of the fibronectin EDA exon is essential for proper skin wound healing and normal lifespan. J Cell Biol. 2003; 162:149160 .

45. Wang Y, Zhou Y, Graves DT. FOXO transcription factors: Their clinical significance and regulation. Biomed Res Int. 2014; 2014:925350.

46. Chiribau CB, Cheng L, Cucoranu IC, Yu YS, Clempus $\mathrm{RE}$, Sorescu D. FOXO3A regulates peroxiredoxin III expression in human cardiac fibroblasts. J Biol Chem. 2008; 283:8211-8217.

47. Fu Z, Tindall DJ. FOXOs, cancer and regulation of apoptosis. Oncogene. 2008; 27:2312-2319.

48. Brent MM, Anand R, Marmorstein R. Structural basis for DNA recognition by FoxO1 and its regulation by posttranslational modification. Structure. 2008; 16:14071416.

49. Hosaka T, Biggs WH, 3rd, Tieu D, Boyer AD, Varki NM, Cavenee WK, Arden KC. Disruption of forkhead transcription factor (FOXO) family members in mice reveals their functional diversification. Proc Natl Acad Sci U S A. 2004; 101:2975-2980.

50. Lin L, Hron JD, Peng SL. Regulation of NF-kappaB, Th activation, and autoinflammation by the forkhead transcription factor Foxo3a. Immunity. 2004; 21:203213.

51. Renault VM, Rafalski VA, Morgan AA, Salih DA, Brett JO, Webb AE, Villeda SA, Thekkat PU, Guillerey C, Denko NC, Palmer TD, Butte AJ, Brunet A. FoxO3 regulates neural stem cell homeostasis. Cell Stem Cell. 2009; 5:527-539.

52. Zhou W, Cao Q, Peng Y, Zhang QJ, Castrillon DH, DePinho RA, Liu ZP. FoxO4 inhibits NF-kappaB and protects mice against colonic injury and inflammation. Gastroenterology. 2009; 137:1403-1414.

53. Salih DA, Rashid AJ, Colas D, et al. FoxO6 regulates memory consolidation and synaptic function. Genes Dev. 2012; 26:2780-2801.

54. Coomans de Brachene A, Demoulin JB. FOXO transcription factors in cancer development and therapy. Cell Mol Life Sci. 2016; 73:1159-1172.

55. Eijkelenboom A, Burgering BM. FOXOs: Signalling integrators for homeostasis maintenance. Nat Rev Mol Cell Biol. 2013; 14:83-97.

56. Matsuzaki H, Daitoku H, Hatta M, Tanaka K, Fukamizu A. Insulin-induced phosphorylation of FKHR (Foxo1) targets to proteasomal degradation. Proc Natl Acad Sci U S A. 2003; 100:11285-11290.

57. Alcendor RR, Gao S, Zhai P, Zablocki D, Holle E, Yu X, Tian B, Wagner T, Vatner SF, Sadoshima J. Sirt1 regulates aging and resistance to oxidative stress in the heart. Circ Res. 2007; 100:1512-1521.

58. Yang JY, Zong CS, Xia W, et al. ERK promotes tumorigenesis by inhibiting FOXO3a via MDM2mediated degradation. Nat Cell Biol. 2008; 10:138-148.

59. Hu MC, Lee DF, Xia W, Golfman LS, Ou-Yang F, Yang JY, Zou Y, Bao S, Hanada N, Saso H, Kobayashi R, Hung MC. IkappaB kinase promotes tumorigenesis 
through inhibition of forkhead FOXO3a. Cell. 2004; 117:225-237.

60. Rena G, Woods YL, Prescott AR, Peggie M, Unterman TG, Williams MR, Cohen P. Two novel phosphorylation sites on FKHR that are critical for its nuclear exclusion. EMBO J. 2002; 21:2263-2271.

61. Das SK, Wang W, Zhabyeyev P, Basu R, McLean B, Fan D, Parajuli N, DesAulniers J, Patel VB, Hajjar RJ, Dyck JR, Kassiri Z, Oudit GY. Iron-overload injury and cardiomyopathy in acquired and genetic models is attenuated by resveratrol therapy. Sci Rep. 2015; 5:18132.

62. Desmouliere A, Redard M, Darby I, Gabbiani G. Apoptosis mediates the decrease in cellularity during the transition between granulation tissue and scar. Am J Pathol. 1995; 146:56-66.

63. Niu Y, Xie T, Ge K, Lin Y, Lu S. Effects of extracellular matrix glycosylation on proliferation and apoptosis of human dermal fibroblasts via the receptor for advanced glycosylated end products. Am J Dermatopathol. 2008; 30:344-351.

64. Alikhani M, Alikhani Z, Graves DT. FOXO1 functions as a master switch that regulates gene expression necessary for tumor necrosis factor-induced fibroblast apoptosis. J Biol Chem. 2005; 280:12096-12102.

65. Wang XW, Yu Y, Gu L. Dehydroabietic acid reverses TNF-alpha-induced the activation of FOXO1 and suppression of TGF-beta1/Smad signaling in human adult dermal fibroblasts. Int J Clin Exp Pathol. 2014; 7:8616-8626.

66. Yamaguchi Y, Madhyastha H, Madhyastha R, Choijookhuu N, Hishikawa Y, Pengjam Y, Nakajima Y, Maruyama M. Arsenic acid inhibits proliferation of skin fibroblasts, and increases cellular senescence through ROS mediated MST1-FOXO signaling pathway. J Toxicol Sci. 2016; 41:105-113.

67. Essaghir A, Dif N, Marbehant CY, Coffer PJ, Demoulin JB. The transcription of FOXO genes is stimulated by FOXO3 and repressed by growth factors. J Biol Chem. 2009; 284:10334-10342.

68. Coomans de Brachene A, Bollaert E, Eijkelenboom A, de Rocca Serra A, van der Vos KE, Burgering BM, Coffer PJ, Essaghir A, Demoulin JB. The expression of the tumour suppressor HBP1 is down-regulated by growth factors via the PI3K/PKB/FOXO pathway. Biochem J. 2014; 460:25-34.

69. Desta T, Li J, Chino T, Graves DT. Altered fibroblast proliferation and apoptosis in diabetic gingival wounds. J Dent Res. 2010; 89:609-614.

70. Siqueira MF, Li J, Chehab L, Desta T, Chino T, Krothpali N, Behl Y, Alikhani M, Yang J, Braasch C, Graves DT. Impaired wound healing in mouse models of diabetes is mediated by TNF-alpha dysregulation and associated with enhanced activation of forkhead box O1 (FOXO1). Diabetologia. 2010; 53:378-388.

71. Kolodsick JE, Peters-Golden M, Larios J, Toews GB, Thannickal VJ, Moore BB. Prostaglandin E2 inhibits fibroblast to myofibroblast transition via E. prostanoid receptor 2 signaling and cyclic adenosine monophosphate elevation. Am J Respir Cell Mol Biol. 2003; 29:537-544.

72. Garrison G, Huang SK, Okunishi K, Scott JP, Kumar Penke LR, Scruggs AM, Peters-Golden M. Reversal of myofibroblast differentiation by prostaglandin E(2). Am J Respir Cell Mol Biol. 2013; 48:550-558.

73. Naini SM, Choukroun GJ, Ryan JR, Hentschel DM, Shah JV, Bonventre JV. Cytosolic phospholipase A2alpha regulates $\mathrm{G} 1$ progression through modulating FOXO1 activity. FASEB J. 2016; 30:1155-1170.

74. Adachi M, Osawa Y, Uchinami H, Kitamura T, Accili D, Brenner DA. The forkhead transcription factor FoxO1 regulates proliferation and transdifferentiation of hepatic stellate cells. Gastroenterology. 2007; 132:1434-1446.

75. Garcia-Monzon C, Lo Iacono O, Mayoral R, GonzalezRodriguez A, Miquilena-Colina ME, Lozano-Rodriguez T, Garcia-Pozo L, Vargas-Castrillon J, Casado M, Bosca L, Valverde AM, Martin-Sanz P. Hepatic insulin resistance is associated with increased apoptosis and fibrogenesis in nonalcoholic steatohepatitis and chronic hepatitis C. J Hepatol. 2011; 54:142-152.

76. Pramod S, Shivakumar K. Mechanisms in cardiac fibroblast growth: An obligate role for Skp2 and FOXO3a in ERK1/2 MAPK-dependent regulation of p27kip1. Am J Physiol Heart Circ Physiol. 2014; 306:H844-855.

77. Pei XM, Yung BY, Yip SP, Chan LW, Wong CS, Ying M, Siu PM. Protective effects of desacyl ghrelin on diabetic cardiomyopathy. Acta Diabetol. 2015; 52:293-306.

78. Lin $\mathrm{CH}$, Lin $\mathrm{CC}$, Ting WJ, Pai PY, Kuo CH, Ho TJ, Kuo WW, Chang CH, Huang CY, Lin WT. Resveratrol enhanced FOXO3 phosphorylation via synergetic activation of SIRT1 and PI3K/Akt signaling to improve the effects of exercise in elderly rat hearts. Age (Dordr). 2014; 36:9705.

79. Yoon HE, Kim SJ, Kim SJ, Chung S, Shin SJ. Tempol attenuates renal fibrosis in mice with unilateral ureteral obstruction: The role of PI3K-Akt-FoxO3a signaling. J Korean Med Sci. 2014; 29:230-237.

80. Bijkerk R, de Bruin RG, van Solingen C, van Gils JM, Duijs JM, van der Veer EP, Rabelink TJ, Humphreys BD, van Zonneveld AJ. Silencing of microRNA-132 reduces renal fibrosis by selectively inhibiting myofibroblast proliferation. Kidney Int. 2016; 89:1268-1280.

81. Nho RS, Peterson M, Hergert P, Henke CA. FoxO3a (Forkhead Box O3a) deficiency protects Idiopathic Pulmonary Fibrosis (IPF) fibroblasts from type I polymerized collagen matrix-induced apoptosis via caveolin-1 (cav-1) and Fas. PLoS One. 2013; 8:e61017.

82. Nho RS, Hergert P, Kahm J, Jessurun J, Henke C. Pathological alteration of FoxO3a activity promotes idiopathic pulmonary fibrosis fibroblast proliferation on type I collagen matrix. Am J Pathol. 2011; 179:24202430.

83. Nho RS, Im J, Ho YY, Hergert P. MicroRNA-96 inhibits FoxO3a function in IPF fibroblasts on type I collagen matrix. Am J Physiol Lung Cell Mol Physiol. 2014; 307:L632-642.

84. Im J, Hergert P, Nho RS. Reduced FoxO3a expression causes low autophagy in idiopathic pulmonary fibrosis fibroblasts on collagen matrices. Am J Physiol Lung Cell Mol Physiol. 2015; 309:L552-561.

85. Li A, Wang J, Wu M, Zhang X, Zhang H. The inhibition of activated hepatic stellate cells proliferation by arctigenin through $\mathrm{G} 0 / \mathrm{G} 1$ phase cell cycle arrest: Persistent p27(Kip1) induction by interfering with PI3K/ Akt/FOXO3a signaling pathway. Eur J Pharmacol. 2015; 747:71-87.

86. Park SJ, Sohn HY, Yoon J, Park SI. Down-regulation of FoxO-dependent c-FLIP expression mediates TRAILinduced apoptosis in activated hepatic stellate cells. Cell Signal. 2009; 21:1495-1503.

87. Kyoung Kim H, Kyoung Kim Y, Song IH, Baek SH, Lee 
SR, Hye Kim J, Kim JR. Down-regulation of a forkhead transcription factor, FOXO3a, accelerates cellular senescence in human dermal fibroblasts. J Gerontol A Biol Sci Med Sci. 2005; 60:4-9.

88. Wang $\mathrm{YN}, \mathrm{Wu} \mathrm{W}$, Chen HC, Fang H. Genistein protects against UVB-induced senescence-like characteristics in human dermal fibroblast by p66Shc down-regulation. J Dermatol Sci. 2010; 58:19-27.

89. You H, Jang Y, You-Ten AI, Okada H, Liepa J, Wakeham A, Zaugg K, Mak TW. p53-dependent inhibition of FKHRL1 in response to DNA damage through protein kinase SGK1. Proc Natl Acad Sci U S A. 2004;
101:14057-14062.

90. Zhu J, Mounzih K, Chehab EF, Mitro N, Saez E, Chehab FF. Effects of FoxO4 overexpression on cholesterol biosynthesis, triacylglycerol accumulation, and glucose uptake. J Lipid Res. 2010; 51:1312-1324.

91. Zhu J, Jiang X, Chehab FF. FoxO4 interacts with the sterol regulatory factor SREBP2 and the hypoxia inducible factor HIF2alpha at the CYP51 promoter. J Lipid Res. 2014; 55:431-442.

(Received January 20, 2017; Revised February 18, 2017; Accepted February 19, 2017) 